\title{
DIVERSIDADE DE INSETOS DO PARQUE ECOLÓGICO DO CÓRREGO GRANDE: EDUCAÇĀO AMBIENTAL E CONSERVAÇĀO
}

\author{
Malva Isabel Medina Hernández \\ Universidade Federal de Santa Catarina \\ malva.medina@ufsc.br \\ Daniella Helena Hock \\ Universidade Federal de Santa Catarina \\ daniellahock@hotmail.com
}

\section{Resumo}

Os insetos desempenham papéis importantes em processos ecossistêmicos, como controle populacional de plantas e animais, polinização de flores, dispersão de sementes, ciclagem de matéria orgânica e de nutrientes e conversão de biomassa vegetal em biomassa animal. Embora estejam intimamente integrados à cultura humana por causa de sua ampla distribuição geográfica, muitas vezes os insetos estão fortemente associados com nocividade. Através do projeto "Diversidade de insetos no Parque Ecológico do Córrego Grande: Educação Ambiental e Conservação", informações biológicas e ecológicas sobre os insetos são disseminadas à população de Florianópolis, SC. O projeto atingiu um total de 6.216 atendimentos, dos quais 4.946 foram constituídos de estudantes em visitas escolares, representando $80 \%$ do total. Assim, o projeto atinge um número importante de pessoas, fazendo com que a importância dos insetos nos sistemas ecológicos seja compreendida, podendo influenciar em comportamentos de respeito aos seres vivos, que podem ser adotados pelo público e passados às futuras gerações.

Palavras-chave: Ecologia. Etnoentomologia. Criação de insetos

\section{INSECT DIVERSITY OF THE CORREGO GRANDE ECOLOGICAL PARK: ENVIRONMENTAL EDUCATION AND CONSERVATION}

\begin{abstract}
Insects play important roles in ecosystem processes through their interaction with natural resources, which includes controlling population of plants and animals, pollinating flowers, scattering seeds, recycling organic matter and nutrients, and converting plant biomass into animal biomass. Although insects are thoroughly integrated into human culture because of their widespread geographical distribution, they are commonly associated with noxiousness. Through the project, "Insect diversity at Parque Ecologico do Corrego Grande: Environmental Education and Conservation", biological and ecological information about insects has been disseminated to the broader population of Florianopolis. The project reached a total of 6,216 attendees, which 4,946 were students on scholarly visits, thus accounting for $80 \%$ of the total. Thus, the project attracts a significant number of people, consequently the importance of insects in ecological systems is understood and can influence respectful behavior to living species, which can be adopted by the public and passed on to future generations.
\end{abstract}

Keywords: Ecology. Ethnoentomology. Rearing insects

\section{DIVERSIDAD DE INSECTOS DEL PARQUE ECOLÓGICO DEL CÓRREGO GRANDE: EDUCACIÓN AMBIENTAL Y CONSERVACIÓN}

\section{Resumen}

Los insectos juegan un papel importante en los procesos ecosistémicos, como control poblacional de animales y plantas, polinización de flores, dispersión de semillas, reciclaje de materia orgánica y nutrientes y la conversión de biomasa vegetal en biomasa animal. A pesar de que están estrechamente integradosa la cultura humana debido a su amplia distribución geográfica, a menudo los insectos están fuertemente asociados con acciones dañinas. A través del proyecto "Diversidad de Insectos en el Parque Ecológico del Córrego Grande: Educación Ambiental y Conservación", informaciones biológicas y 


\section{BXTPUSHI

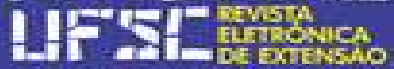

ecológicas acerca de los insectos son difundidas a la población de Florianópolis, SC. El proyecto alcanzó un total de 6.216 personas, de las cuales 4.946 fueron estudiantes en visitas escolares, que representan el $80 \%$ del total. Por lo tanto, el proyecto llega a un número significativo de personas, propiciando la comprensión acerca de la importancia de los insectos en los sistemas ecológicos, pudiendo así influir en un comportamiento de respeto a los seres vivos, que pueden ser adoptados por el público y transmitidos a las generaciones futuras.

Palabras clave: Ecología. Etnoentomología. Crianza de insectos 
Diversidade de insetos do Parque Ecológico do Córrego Grande: educaçāo ambiental e conservaçāo

\section{INTRODUÇÃO}

Os insetos são encontrados em praticamente todos os ecossistemas e participam de diversos processos ecológicos como: dispersão de sementes, ciclagem de matéria orgânica, polinização de plantas com flores, dispersão de fungos, fonte de alimento para outros animais, controle populacional de espécies de plantas através da herbivoria e de animais pela disseminação de doenças e parasitismo (BORROR \& DELONG 1988; SILVA, ALVES e GIANNOTTTI 2006). Este grupo é considerado um sucesso evolutivo, compondo a forma de vida mais diversificada na Terra, com um número próximo a um milhão de espécies descritas, o que representa mais da metade de todos os organismos já identificados, sendo este número ainda maior quando consideramos as espécies que ainda são desconhecidas para a ciência (CRANSTON e GULLAN, 2012). Além da diversidade taxonômica, os insetos apresentam alta diversidade de comportamentos, como os diversos tipos de hábitos alimentares ou de locomoção; de tamanho e forma corporal (HERNÁNDEZ et al., 2011), considerando desde as diferenças entre as fases do ciclo de vida até a variação intra e interespecífica; de utilização de habitats, vivendo em ambientes aquáticos, florestais e até desérticos; além de ampla coloração (HERNÁNDEZ, 2002).

Devido a sua grande distribuição geográfica e abundância, os insetos corriqueiramente estão presentes na vida das pessoas em diferentes experiências, acarretando julgamentos por parte delas. O campo de estudo que trata da interação, percepção, utilização, conhecimento e crenças a respeito dos insetos pelas populações humanas é denominado de etnoentomologia (POSEY, 1987; BERLIN, 1992; COSTA NETO, 2004). A percepção geral sobre os insetos é construída através da vivência individual ou de uma comunidade, com a influência cultural deste grupo se estendendo também à literatura, música, folclore, artes plásticas, culinária, cinema e religião em diferentes sociedades, tanto remotas quanto contemporâneas (COSTA NETO, 2002). Mas, devido ao distanciamento entre o homem e a natureza, nota-se que esta construção da percepção atualmente está mais associada às diferentes abordagens transmitidas pelos meios de comunicação e, em geral, com poucas informações sobre este grupo animal (COSTA NETO, 2004).

Embora fundamentais para a manutenção do funcionamento dos ecossistemas, as ideias na sociedade a respeito dos insetos são frequentemente depreciativas mesmo que somente $10 \%$ das espécies descritas possam ser consideradas vetores de doenças ou pragas (COSTA NETO, 2002; MODRO et al., 2009; TRINDADE et al. 2012; SOUZA JUNIOR et al., 2014). Trindade e colaboradores (2012) demonstraram, através da expressão apresentada por alunos de ensino 


\section{EXIPNEHI

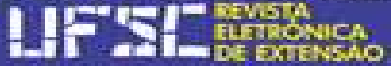

médio na observação de figuras de diversos organismos, que os insetos desenvolveram 10 vezes mais expressões depreciativas quando comparados aos outros grupos animais. Esta visão pejorativa e de nocividade está arraigada culturalmente até na palavra inseto, já que no senso comum, a denominação "inseto" abrange outros animais - como aranhas e cobras - pertencentes a outros grupos taxonômicos, mas com características de periculosidade ou nocividade (COSTA NETO e CARVALHO, 2000; MODRO et. al., 2009).

$\mathrm{Na}$ tentativa de levar à comunidade de Florianópolis informações sobre a biologia e ecologia dos insetos, bem como proporcionar uma experiência de contato com insetos vivos que permita desmistificar preconceitos, o projeto "Diversidade de insetos do Parque Ecológico do Córrego Grande: educação ambiental e conservação" busca através destas experiências difundir o conhecimento, permitindo uma propagação positiva para a sociedade sobre os insetos nos ecossistemas.

\section{MATERIAIS E MÉTODOS}

O projeto é desenvolvido de forma contínua desde o ano 2008 dentro do Parque Ecológico Municipal Prof. João David Ferreira Lima, no bairro do Córrego Grande, na cidade de Florianópolis, Santa Catarina. O parque recebe diariamente a população em geral e alunos de escolas públicas e particulares que, através do agendamento com a equipe de educação ambiental da Fundação Municipal do Meio Ambiente de Florianópolis - FLORAM visitam o quiosque dos insetos como uma das atividades de educação ambiental.

Dentro de um quiosque de madeira (número 8) de aproximadamente $5 \mathrm{~m}^{2}$, os insetos coletados, de diferentes espécies nativas da Ilha de Santa Catarina, são criados em terrários de vidro fechados superiormente por uma cobertura feita de tecido voal, a qual permite a circulação do ar. Estudantes do Curso de Ciências Biológicas da UFSC, bolsistas do projeto de extensão, são os responsáveis pela limpeza dos terrários e da estrutura, bem como da alimentação específica de cada animal, a fim de proporcionar condições adequadas à sobrevivência, bem-estar e reprodução dos mesmos, além de observar e registrar os ciclos de vida e as características de cada animal, suas relações com o ambiente e com os demais organismos.

Além dos cuidados com os insetos, os bolsistas são responsáveis pelo atendimento aos visitantes, que é realizado em diversos horários, e da distribuição de materiais informativos sobre o ciclo de vida das borboletas mais frequentemente encontradas no parque. As palestras realizadas aos visitantes tem duração de cerca de 15 minutos, sendo adaptadas para cada faixa 


\section{EXTENSHI

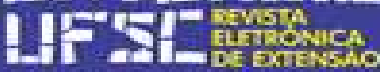

etária e conhecimento prévio demonstrado pelo público. Durante este tempo, alguns exemplares de cada espécie são apresentados em pequenos terrários de vidro. Os insetos inofensivos podem ser manuseados pelos ministrantes e pelo próprio público, que é previamente orientado sobre como tocá-los. Cartazes com fotos de outros insetos já criados e esquemas do ciclo de vida são disponibilizados junto à palestra para visualização, a fim de ajudar na compreensão do público.

As informações recolhidas após cada visita incluem o registro do dia e do horário das visitas, do número de visitantes atendidos, bem como a faixa etária ou ano escolar, o número de professores acompanhantes e o nome da instituição de ensino a qual pertenciam os alunos, e o nome do aluno bolsista que ministrou a palestra.

\section{RESULTADOS E ANÁLISE}

Durante os seis anos de andamento do projeto, diversas espécies de insetos foram criadas pelos bolsistas e voluntários com o intuito de atraírem a atenção, análise e interesse do público (Figura 1). As espécies que foram mais facilmente criadas pertenciam ao grupo dos coleópteros (besouros) e dos lepidópteros (borboletas), já que são facilmente alimentados e podem ser mantidos sob condições adequadas de temperatura, umidade e espaço disponível.

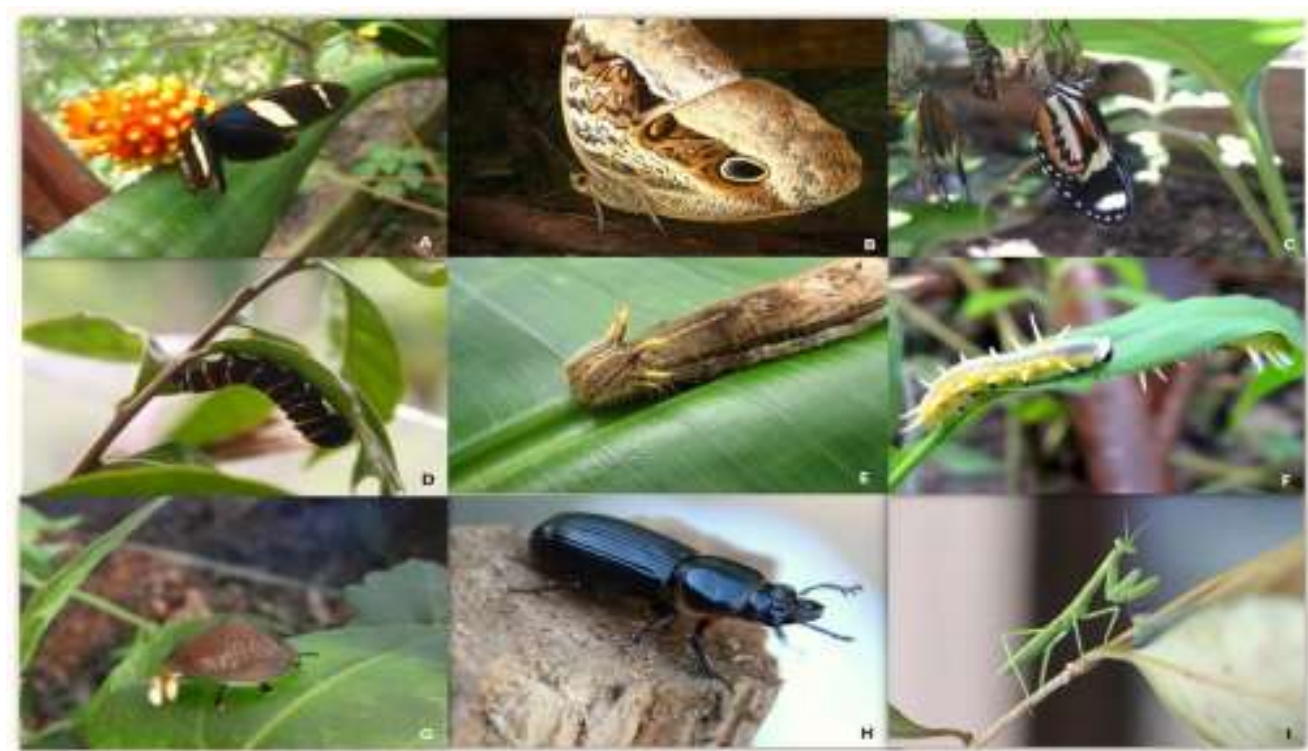

Figura 1 - Principais espécies de insetos mostrados ao público visitante do projeto "Diversidade de Insetos no Parque Ecológico do Córrego Grande: educaşão ambiental e conservação" em Florianópolis, Santa Catarina, durante os anos 2008 a 2013.

Fonte: Elaborado pelos autores, 2015. 


\section{BXTPMSHI

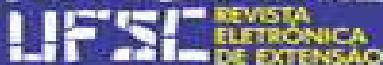

Para estabelecer a compreensão do ciclo de vida e das transformações que os insetos sofrem, já que muitas espécies apresentam metamorfose, foram apresentadas formas imaturas e completamente diferentes dos adultos durante as palestras (Figura 2). Esta era uma das dúvidas mais sanadas para o público, que acreditava que lagartas eram espécies diferentes das borboletas ou que besouros têm a mesma forma durante toda a sua vida.

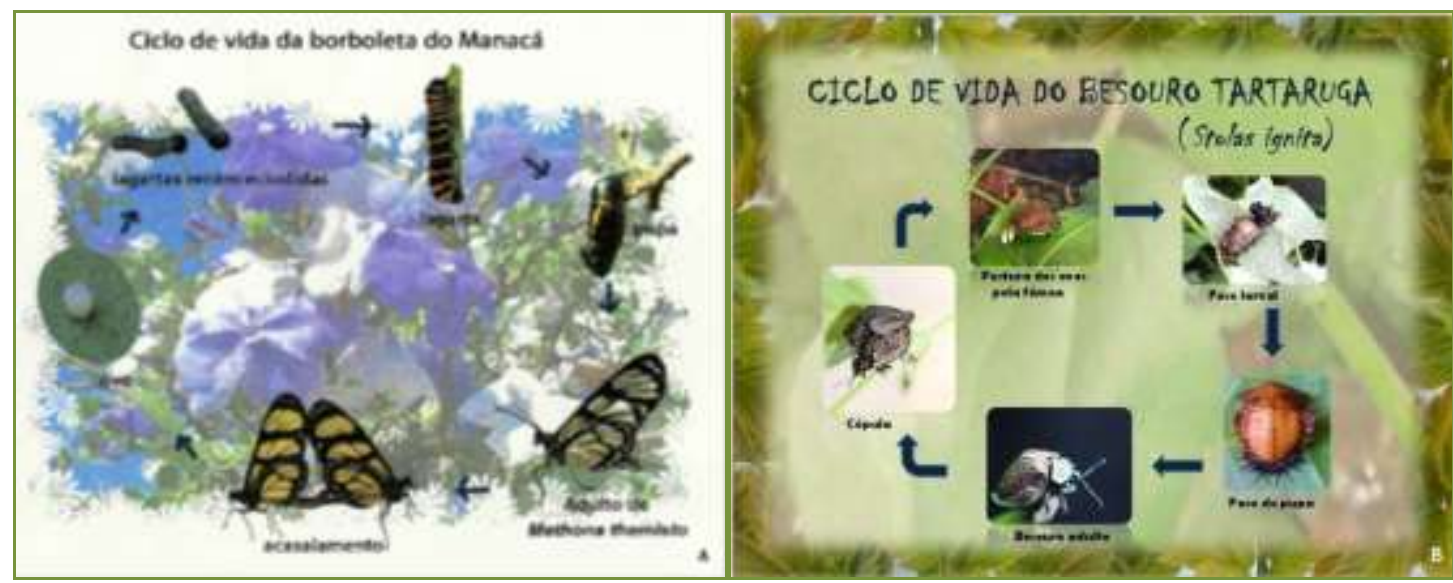

Figura 2 - Ciclos de vida de (A) borboletas e (B) besouros apresentados ao público visitante do projeto de Educação Ambiental.

Fonte: Elaborado pelos autores, 2015.

Besouros da espécie Stolas ignita (Boheman, 1850) (Figura 1G), conhecidos como besouros tartaruga, são apresentados pelo projeto desde o ano de 2011, quando foram coletadas duas fêmeas e, desde então, apresentam sucesso reprodutivo favorável para sua criação em cativeiro, se alimentando de uma planta da família Asteraceae, muito comum no parque. Diferentes fases dos estádios de vida desta espécie podem ser obtidas em um mesmo período de tempo, facilitando a compreensão por parte do público quanto às mudanças pelas quais os besouros - mas também os insetos em geral - sofrem durante o ciclo de vida (Figura 2B).

O besouro tartaruga é uma espécie carismática, atraindo a atenção e simpatia das pessoas, devido à sua aparência similar a uma tartaruga e pela sua beleza e coloração em diferentes tonalidades. Além disso, assim como todos os besouros, eles não apresentam nenhum tipo de nocividade. No ano de 2013, houve um grande sucesso na criação destes insetos, alcançando mais de 200 ovos nos meses de agosto e setembro e em torno de 80 indivíduos adultos no mês de novembro, os quais foram soltos no próprio espaço do parque onde foram encontrados junto à sua planta hospedeira. 


\section{EXIPUNHI

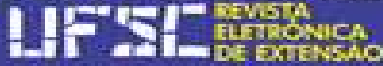

Também a manutenção de besouros da Família Passalidae (Figura 1H) foi bem sucedida, já que esses animais apresentaram um comportamento apropriado ao cativeiro e à manipulação aos visitantes, uma vez que não são voadores. Por se alimentarem e viverem em troncos de madeira em decomposição participam da ciclagem da matéria orgânica nos ecossistemas. Eles são conhecidos popularmente como besouros chim-chim, devido ao som que produzem nos aparatos estridulatórios localizados na parte dorsal do corpo e tem função de comunicação entre os indivíduos. Quando manuseados, produziam estes sons que capturavam e favoreciam a atenção do público ao tema apresentado.

Muitas espécies de borboletas foram criadas, principalmente borboletas frugívoras, que são facilmente criadas por se alimentarem na fase adulta de fruta em decomposição (CORSO e HERNÁNDEZ, 2012). A espécie Caligo beltrao (Illiger, 1801), conhecida como borboleta-coruja (Figura 1B), foi criada em várias gerações com sucesso durante o projeto, sendo suas larvas alimentadas com folhas de banana caeté (Figura 1E).

No ano 2011 foram criados 27 exemplares de Methona themisto (Hübner, 1818), a borboleta do Manacá, devido à sua grande beleza. Estas borboletas são bastante comuns, de fácil manutenção e as lagartas não apresentam perigo. As lagartas foram alimentadas com sua planta hospedeira, o Manacá de Cheiro, Brunfelsia uniflora [(Pohl) D. Don], até que seus exemplares adultos estivessem aptos à soltura. O ciclo de vida a partir da lagarta até a metamorfose completa durou o período de aproximadamente um mês. Como os adultos se alimentam do néctar das flores, não era viável mantê-las em cativeiro sem uma produção de flores, portanto, na presença de crianças em visitas escolares ou da comunidade, eram soltas ao ambiente.

Insetos que estão vinculados ao mito de serem venenosos são o bicho-pau e o louvadeus. Mesmo quando o projeto não contava com a presença destes exemplares, os bolsistas eram questionados se estes animais eram venenosos ou não. Depois de esclarecido que o louva-deus não é venenoso e que se alimenta de pequenos insetos, não apresentando perigo, assim como o bicho-pau, que se alimenta de folhas, comportamentos relatados previamente pelo público aos bolsistas eram corrigidos por eles mesmos, no caso de futuros contatos com estes insetos, demonstrando que o retorno da assimilação da informação que o projeto deseja transmitir em algumas situações era registrado rapidamente. Além disto, grande parte do público atendido comentava que passaria esta informação para conhecidos que eventualmente apresentavam comportamentos "agressivos" com estas espécies.

A percepção distorcida do público quando se trata dos insetos se torna evidente quando, apesar do quiosque do projeto apresentar uma placa escrita "Insetário", as pessoas questionam 


\section{EXTPNSHI

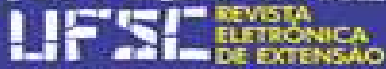

sobre a criação de cobras ou aranhas, sempre apresentando expressões de rejeição. Quando devidamente explicada a diferença entre os grupos animais e de que o projeto tem o propósito de passar as informações à comunidade, era notável a mudança comportamental assumida em relação aos insetos da criação após a compreensão de parte da biologia dos mesmos.

As crianças em visitas escolares eram abordadas frequentemente com perguntas sobre os insetos, para que demonstrassem interesse e interação com o tema, além de uma percepção da assimilação dos conteúdos ministrados anteriormente na palestra. A manipulação dos insetos era a parte na qual o público se apresentava mais eufórico e atento, prestando atenção aos detalhes morfológicos e beleza dos animais. Em muitos casos, mesmo com os colegas e professores manipulando os insetos, alguns alunos apresentavam comportamento de pânico, medo ou de evitar os insetos que eram apresentados conforme o tempo disponível da visita ao parque.

Os atendimentos contabilizados após cada visita estão apresentados na Figura 3, onde se observa a abrangência direta do projeto por ano, subdividido em número de pessoas atendidas da população em geral e das escolas (incluindo professores e alunos). Do número total de pessoas atendidas durante os seis anos de projeto, que chegaram a 6.216 visitantes, grande parte se refere a alunos e professores em visitas escolares, com 4.946 pessoas atendidas.

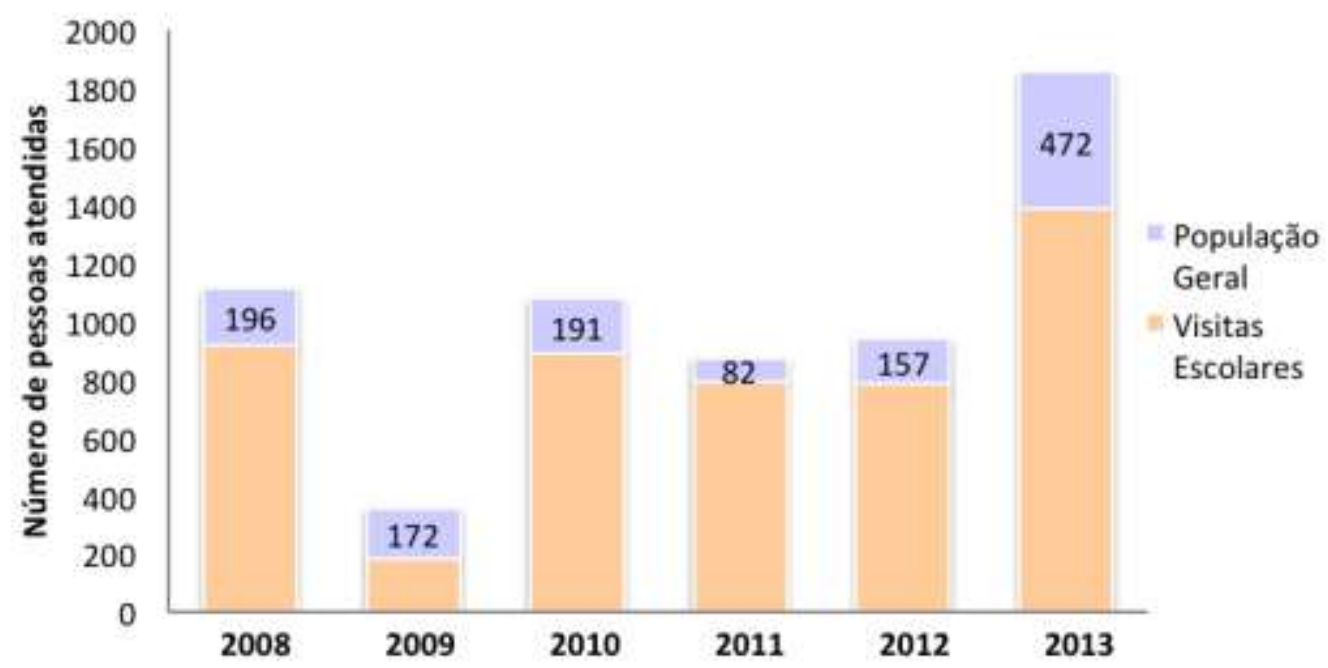

Figura 3 - Número de pessoas atendidas pelos bolsistas do projeto de extensão no período de 2008 a 2013 no Parque Ecológico do Córrego Grande, Florianópolis, SC. Fonte: Elaborado pelos autores, 2015.

O público visitante do projeto é preferencialmente composto por crianças do ensino infantil e fundamental em visitas escolares, representando $80 \%$ dos atendimentos (Figura 4). 


\section{EXTPMSHI

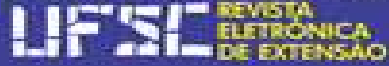

Esta grande abrangência de atendimento do projeto às crianças permite que o conhecimento adquirido sobre os insetos seja transmitido aos pais e familiares, transformando não somente as futuras gerações através das crianças, mas também as atuais gerações.

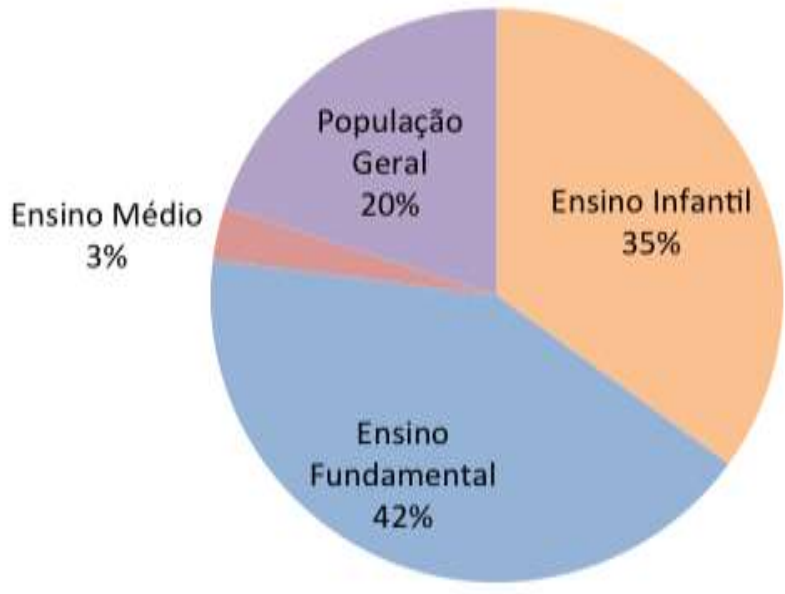

Figura 4 - Perfil do público visitante do projeto de extensão sobre os Insetos do Parque Ecológico do Córrego Grande em Florianópolis, SC e porcentagem dos atendimentos realizados pelos bolsistas do projeto no período de 2008 a 2013.

Fonte: Elaborado pelos autores, 2015.

Além do projeto desenvolvido no espaço do parque, o projeto "Sala de aula" foi desenvolvido paralelamente nos anos 2009 e 2011 em salas de aula de duas escolas, sendo o primeiro na Escola Sarapiquá - Itacorubi, envolvendo uma turma de 25 crianças do $4^{\circ}$ ano de ensino fundamental, realizada em conjunto com a professora de Ciências e o segundo foi desenvolvido com 82 crianças de primeira e segunda séries da Escola Laércio Caldeira de Andrada - Campinas. Ambos os projetos puderam contar com relatos posteriores das professoras quanto ao conteúdo, que foi amplamente assimilado e justificado pelas posturas que os alunos apresentaram em sala de aula, como a presença de maior estímulo na realização das atividades escolares quando relacionadas ao projeto e também com o cuidado com os insetos e plantas no entorno da escola. Em resumo, os resultados deste projeto paralelo foi uma afirmação de que o contato com insetos vivos pode ser uma ferramenta qualitativa para a criação de estratégias que visem à conservação da natureza e respeito a todas as formas de vida.

A participação do projeto em eventos realizados, inseridos ou não nas dependências do parque, como exemplo: Bio na Rua/UFSC, Bio na Escola/UFSC, SEPEX/UFSC, Mostra Sr. Inseto, Muito Prazer!, Semana do Meio Ambiente e congressos nacionais foram importantes na 


\section{EXTENEHI IfF}

extensão das informações sobre os insetos e sobre o projeto para um maior grupo de pessoas e localidades, dados não contabilizados na Figura 3.

\section{CONSIDERAÇÕES FINAIS}

A criação dos insetos tem como finalidade a apresentação à comunidade e estudantes de insetos vivos para que se estabeleça uma aproximação com os mesmos, a fim de proporcionar uma experiência agradável e informativa deste grupo animal. Uma vez que se compreende a importância dos insetos nos sistemas biológicos, espera-se que comportamentos que os valorizem sejam adotados e transmitidos entre as gerações.

O público atendido durante os anos de projeto atingiu um número bastante relevante, desde as visitas nas dependências do parque que somam mais de seis mil pessoas até em eventos onde não foi contabilizado o público atendido. Além do mais, torna-se impossível estimar a quantidade de pessoas que receberam o repasse posterior das informações que foram adquiridas através dos bolsistas do projeto.

Vale ressaltar que em algumas situações o retorno dos conhecimentos repassados à comunidade ou alunos foi estimado através de depoimentos de pais após as visitas e de desenhos produzidos pelos próprios alunos após as palestras. Isto demonstra que o projeto aqui descrito, que continua sendo realizado, cumpre com o seu objetivo de ser um método efetivo de transmissão dos conhecimentos básicos de ecologia e biologia dos insetos na manutenção da função dos ecossistemas a fim de estabelecer uma consciência da comunidade em todas as suas idades.

\section{AGRADECIMENTOS}

À Pró-reitoria de Extensão - PROEX, da Universidade Federal de Santa Catarina (Edital PROBOLSAS) pelas bolsas de extensão recebidas pelos alunos participantes do Projeto de Extensão "Diversidade de insetos do Parque Ecológico do Córrego Grande: educação ambiental e conservação". Ao Prof. Dr. Benedito Cortês Lopes, do Departamento de Ecologia e Zoologia da UFSC e a Panmella Kelan Ribeiro Costa por todo o apoio brindado ao projeto, desde seu início. Aos bolsistas que participaram até o momento no projeto: André Ganzarolli Martins e Gabriela Corso 


\section{EXIPNEHI IfF}

da Silva (2008), Ana Letícia Trivia e Daniel Prim Janning (2009), Ana Letícia Trivia e Arthur Prado Fleury Magalhães (2010), Mariah Wuerges (2011) Giancarlo Capistrano e Mayara Cristina Sberse (2012), Daniella Helena Hock e Mari Dalva Staffen (2013). À equipe de Educação Ambiental e demais funcionários do Parque Ecológico do Córrego Grande pelo grande auxílio prestado ao projeto no decorrer dos anos.

\section{REFERÊNCIAS}

BERLIN, N. Ethnobiological classification: principles of categorization of plants and animals in traditional societies. New Jersey, Princeton University Press, 1992.

BORROR, D. J. \& DELONG, D. M. Estudo dos insetos. Editor Edgard Blucher Ltda., São Paulo, 1988.

CORSO, G. \& HERNÁNDEZ, M. I. M. Borboletas frugívoras da Mata Atlântica no Parque Estadual da Serra do Tabuleiro, Santa Catarina, Brasil. Biotemas (UFSC), v. 25, p. 139-148, 2012.

COSTA NETO, E. M. \& CARVALHO, P. D. Percepção dos insetos pelos graduandos da Universidade Estadual de Feira de Santana, Bahia, Brasil. Acta Scientiarium, v. 22, n. 2, p. 423-428, 2000.

COSTA NETO, E. M. Manual de etnoentomologia. Zaragoza: Manuales e Tesis SEA, 2002. .Estudos etnoentomológicos no estado da Bahia, Brasil: uma homenagem aos $\mathbf{5 0}$ anos do campo de pesquisa. Biotemas, v. 17, n. 1, p. 117-149, 2004.

CRANSTON, P. S. \& GULLAN, P. J. Os Insetos - Um Resumo de Entomologia - $4^{a}$ Ed. São Paulo: Editora Roca, 2012. 496p.

HERNÁNDEZ, M. I. M. The night and day of dung beetles (Coleoptera, Scarabaeidae) in the Serra do Japi, Brazil: elytra colour related to daily activity. Revista Brasileira de Entomologia, v.46, p. 597 - 600, 2002.

MONTEIRO, L. R., FAVILA, M. E. The role of body size and body shape in understanding competitive interactions within a community of Neotropical dung beetles. Journal of Insect Science (Online), v.11, p. 1-14, 2011. 


\section{EXIPNEHI

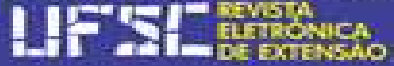

MODRO, A. F. H., COSTA, M. S., MAIA, E., ABURAYA, F. H. Percepção entomológica por docentes e discentes do município de Santa Cruz do Xingu, Mato Grosso, Brasil. Biotemas, v. 22, n. 2, p. 153-159, 2009.

POSEY, D. A. Temas e inquirições em etnoentomologia: algumas sugestões quanto à geração de hipóteses. Boletim do Museu Paraense Emílio Goeldi, Belém, v. 3, n. 2, p. 99-134, 1987.

SILVA, E. R. L., ALVES, L. F. A.; GIANNOTTI, S. M. Análise do conteúdo de Artrópodes em livros didáticos de Biologia do Ensino Médio e o perfil do professor: estudo de caso. Revista Varia Scientia, Cascavel, Paraná, v. 6, n. 11, p. 83-98, 2006

SILVA, T. F. P. \& COSTA NETO, E. M. Percepção de insetos por moradores da comunidade Olhos D’Água, município de Cabaceiras do Paraguaçu, Bahia, Brasil. Boletín de la Sociedad Entomológica Aragonesa, n. 35 p. 261-268, 2004.

SOUZA JUNIOR, E. A., COSTA NETO, E. M., SANTOS, G. C. B. As concepções que estudantes da sexta série do ensino fundamental do Centro de Educação Básica da Universidade Estadual de Feira de Santana possuem sobre os insetos. Gaia Scientia, v. 8, n. 1, p. 08-16, 2014.

TRINDADE, O. S. N.; SILVA JUNIOR, J. C.; TEIXEIRA, P. M. M. Um estudo das representações sociais de estudantes do ensino médio sobre os insetos. Revista Ensaio, Belo Horizonte, v. 14, n. 03, p. 37-50, set-dez 2012. 
ANEXO I - Lista de classificação dos insetos criados e apresentados pelo projeto de extensão "Diversidade de insetos do Parque Ecológico do Córrego Grande: educasaão ambiental e conservação" no período de 2008 a 2013 em Florianópolis, Santa Catarina.

\begin{tabular}{lcc}
\hline \multicolumn{1}{c}{ Ordem: Família } & Nome & Alimentação \\
\hline Coleoptera: Passalidae & Besouro carocha & Troncos podres \\
Coleoptera: Scarabaeidae & Besouro escaravelho Phileurus sp.; Enema pan (Fabricius, 1775) & Troncos podres \\
& Besouro rola-bosta Deltochilum irroratum (Laporte, 1840) Besouro & Fezes e carne em decomposição \\
Coleoptera: Chrysomelidae & rola-bosta Canthon rutilans Laporte, 1840 & Fezes e carne em decomposição \\
Mantodea: Mantidae & Besouro tartaruga Stolas ignita (Boheman, 1850) & Folhas de Asteraceae Calea sp. \\
Lepidoptera: Nymphalidae & Louva-deus & Pequenos insetos \\
& Borboleta tigrada Mechanitis hysimnia (Fabricius, 1793) & Folhas de joá Solanum sp. \\
& Borboleta Adelpha serpa (Boisduval, 1836) & Folhas de Miconia sp. \\
& Borboleta Catonephele acontius (Linnaeus, 1771) & Folhas de tanheiro Alchornea sp. \\
& Borboleta zebra Colobura dirce (Linnaeus, 1758) & Folhas de embaúba Cecropia sp. \\
& Borboleta coruja Caligo beltrao (Illiger, 1801) & Folhas de banana-caeté Heliconia sp. \\
& Borboleta do limoeiro Heraclides anchisiades (Esper, 1788) & Folhas de limoeiro Citrus sp. \\
& Borboleta do maracujazeiro Heliconius ethilla Godart, 1819 & Folhas de maracujá Passiflora sp. \\
Borboleta do manacá Methona themisto (Hübner, 1818) & Folhas de manacá de cheiro Brunfelsia uniflora \\
Borboleta Catonephele numilia (Cramer, 1775) & Folhas de tanheiro Alchornea sp. \\
Borboleta Historis odius (Fabricius, 1775) & Folhas de embaúba Cecropia sp. \\
& Borboleta Opsiphanes invirae (Hübner, 1818) & Coletada pupa em beijo-de-moça Impatiens sp. \\
& Lagarta agrimensora ou mede-palmos & Folhas de limoeiro Citrus sp. \\
\hline
\end{tabular}

